\title{
Call for papers:
}

\section{$N J L$ Special Issue on Sociolinguistics}

The second issue of Volume 32 (December 2009) of the Nordic Journal of Linguistics will be a special issue devoted to sociolinguistics, edited by Frans Gregersen and Unn Røyneland.

Both the study of macro-sociolinguistics (language and society, nationally, regionally, globally, including language policy issues) and the study of microsociolinguistics (variational and interactional sociolinguistics) have witnessed major developments in recent years in all the Nordic countries.

The dialogue between general, theoretical and empirical linguists and sociolinguists is already taking place, often with a focus on a recent convergence of interest in variation at all levels. Simultaneously, new methods have been introduced into Nordic sociolinguistics leaning towards and learning from anthropology and sociology, where a considerable number of theoretical issues have come to the fore, which have as their background the contemporary mixture of dialect-standard societies and multilingual societies deepening already significant differences between rural and urban life.

We therefore feel that the time is right to devote a special issue of Nordic Journal of Linguistics to sociolinguistics, in order to encourage both junior and senior researchers to contribute to the ongoing international discussion of e.g.

- methodology,

- comparative studies,

- the concept of variation, and/or

- the multiplex linguistic nature of the modern metropolitan life and what this entails for sociolinguistics.

We invite papers addressing one or more of these topics, and we are particularly (but not exclusively) looking for contributions that also touch on one or more of the languages spoken in the Nordic countries. The deadline is January 31, 2009. Papers should be sent to:

Frans Gregersen

LANCHART

University of Copenhagen

Njalsgade 136, 27.5

DK-2300 Copenhagen S

Denmark

fg@hum.ku.dk
Unn Røyneland

Dept. of Linguistics and Scandinavian Studies

University of Oslo

P.O. Box 1102 Blindern

NO-0317 Oslo

Norway

unn.royneland@iln.uio.no 